\title{
A pedagogia, a formação humana e o sujeito nar- císico pós-moderno
}

João Francisco Lopes de Lima

Universidade do Porto (Portugal)

\section{Resumo}

Esse estudo, de caráter bibliográfico, considera o tema da subjetividade na Pós-modernidade e analisa o seu impacto para a formulação de enunciados sobre formação humana pela pedagogia. Numa primeira parte, o texto analisa a subjetividade universal como premissa moderna e como essa noção se altera no cenário pós-moderno. Em seguida, caracteriza a subjetividade narcísica, a partir da construção de Gilles Lipovetsky sobre a ideia de sujeito narcísico, e sobre a noção de era do vazio, além de outros autores que tratam sobre o tema do sujeito, do narcisismo e da educação em tempos de Pós-modernidade. Por fim, considera-se a absorção e o impacto da noção de sujeito privatizado na formulação de discursos pedagógicos gerados ou recriados no cenário pós-moderno. O texto destaca o papel da escola como instância de prática da vida pública e oportunidade para o aprendizado de formas de pensamento descentrado e de sujeitos mais fortalecidos em autonomia e capacidade de vida coletiva.

Palavras-chave: Pós-modernidade. Discurso pedagógico. Pedagogia. Narcisismo.

\section{Pedagogy, formation human and the post-modern narcissistic person}

\section{Abstract}

This bibliographical study considers the subject of subjectivity in Postmodernity and analyzes its impact for the formulation of statements about human formation by pedagogy. In the first part, the text analyzes the universal subjectivity as a modern premise and how this notion changes in the postmodern scenario. Next, it characterizes the narcissistic subjectivity, from the construction of Gilles Lipovetsky on the idea of narcissistic person, and on the notion of the era of emptiness, besides other authors that treat on person, the narcissism and the education in times of Postmodernity. Finally, we consider the absorption and impact of the notion of privatized person in the formulation of pedagogical discourses generated or recreated in the postmodern scenario. The text highlights the role of the school as an instance of public life practice and an opportunity for the learning of decentralized forms of thought and of more strengthened persons in autonomy and capacity of collective life.

Keywords: Postmodernity. Pedagogical. Discourse. Pedagogy. Narcissism. 
A pedagogia, a formação humana e o sujeito narcísico pós-moderno

\section{La pedagogia, la formación humana y el sujeto narcisista pos moderno}

\section{Resumen}

Este estudio bibliográfico considera el tema de la subjetividad en la Posmodernidad y analiza su impacto para la formulación de afirmaciones sobre la formación humana por la pedagogía. En la primera parte, el texto analiza la subjetividad universal como una premisa moderna y cómo esta noción cambia en el escenario posmoderno. A continuación, caracteriza la subjetividad narcisista, a partir de la construcción de Gilles Lipovetsky sobre la idea de sujeto narcisista, y sobre la noción de vacío, además de otros autores que tratan el tema del sujeto, el narcisismo y la educación en tiempos de la Posmodernidad. Finalmente, consideramos la absorción y el impacto de la noción de sujeto privatizado en la formulación de los discursos pedagógicos generados o recreados en el escenario posmoderno. El texto destaca el papel de la escuela como un ejemplo de práctica de la vida pública y una oportunidad para el aprendizaje de formas de pensamiento descentralizadas y de sujetos más fortalecidos en autonomía y capacidad de vida colectiva.

Palabras clave: Postmodernidad. Discurso pedagógico. Pedagogía. Narcisismo.

\section{Subjetividade e pedagogia na Modernidade: emancipa ou conforma?}

A educação contemporânea é tributária das formulações filosóficas da Modernidade: o primado da razão, a melhoria do entendimento e a construção da autonomia de pensamento a partir do acesso à cultura e à ciência e, principalmente, do uso desses recursos da formação humana para a constituição da moralidade do sujeito. Um sujeito moralizado, nessa perspectiva, seria um sujeito capaz de fazer boas escolhas e de fazer o uso público da razão. Seria um sujeito capaz de tomar decisões que não fossem boas apenas para ele como indivíduo, mas consideradas válidas para todos os demais.

Esse sujeito é o sujeito epistêmico, um sujeito teórico produzido pela ciência, o "sujeito moderno". Trata-se de uma espécie de síntese epistemológica que sublinha as suas propriedades racionais consideradas universais, portanto disponíveis em todos os indivíduos. A ciência enunciou e a pedagogia incorporou a ideia de que em circunstâncias semelhantes, diante da estabilidade das ações didático-pedagógicas, da regularidade de suas intervenções e da reprodutibilidade dos procedimentos, é possível atingir resultados igualmente semelhantes em distintos grupos. 
Kant (1999), na obra Sobre a pedagogia, apontou a base do que se pode chamar de "formação integral" a partir da Modernidade. Para o filósofo, a formação humana é ampla e passa pelo uso da razão, do conhecimento científico e dos saberes da cultura para obter a formação intelectual. Essa serviria como recurso para formar o sujeito disciplinado e inserido na vida pública através do trabalho produtivo e de ações corretas moralmente, o que caracterizaria a formação moral do sujeito. Para ele, trata-se, portanto, de uma formação subjetiva que torna o sujeito capaz de estruturar de forma autônoma, livre e reflexiva o seu pensamento. Esse fundo kantiano da lógica moderna nos mostra que a combinação entre formação intelectual, moral e subjetiva gera uma integralidade e uma organicidade na formação humana que será tomada como esperanto da educação derivada da Modernidade, em diferentes narrativas pedagógicas.

A racionalidade moderna gerou a noção de sujeito epistêmico e a pedagogia incorporou-a ao processo educativo. A noção de um sujeito universal, com recursos idênticos e disponíveis em todos os indivíduos, deu sustentação a diferentes teorias pedagógicas. A educação escolar, por sua vez, assumiu a tarefa do aperfeiçoamento do gênero humano como sua tarefa pedagógica mais relevante.

Habermas (2000) considerou a ideia de sujeito e a noção de subjetividade como uma espécie de fisionomia dos tempos modernos, marca fundamental da condição de liberdade e de reflexão do sujeito racional. A ideia de subjetividade, no contexto moderno, é descrita por Habermas em quatro dimensões: o individualismo - no sentido da singularidade e particularidade de cada sujeito; o direito de crítica - no sentido de que, em uma situação pública, é possível expressar avaliações cognitivas e juízos morais, mas é necessário verificar a legitimidade do que é dito; a autonomia da ação - no sentido de que cabe ao sujeito responder pelo que faz; e, por fim, a filosofia idealista - no sentido de que há uma crença no progresso histórico da humanidade e no progresso de cada indivíduo e de que a filosofia possa apreender a ideia que faz de si mesma.

Formar o sujeito "educado", através da educação escolar, para obter socialmente o homem civil, ou seja, o cidadão, é um dos grandes objetivos da educação herdeira da Modernidade. Esse sujeito "educado" indica uma pessoa capaz de uma vida conduzida não apenas por demandas privadas. 
Indica, nesse sentido, alguém capaz de ações responsáveis, que avalia as consequências de seus atos no contexto social.

A crença numa linha de evolução progressiva e natural desse sujeito "educado" gerou uma demanda de disciplinamento dos sujeitos, de esforços na contenção e na domesticação de seus impulsos para que possa se inserir numa "comunidade moral", já que a autonomia, nessa perspectiva, tem uma dimensão pública. Os efeitos de controle sobre o sujeito e das práticas disciplinares foram examinados por inúmeros autores. Foi, possivelmente, Foucault (1987) quem melhor analisou os efeitos do disciplinamento do sujeito (seu corpo, sua palavra, sua sexualidade, existência) na sociedade moderna. Sem o controle disciplinar desempenhado pelas estratégias coercitivas das instâncias educadoras (família, escola, igreja e outras instituições), dificilmente se obteria uma subjetividade suficientemente "conformada" ao processo educativo. Nesse sentido, educar é reprimir, conter, dobrar, docilizar a animalidade, o instinto, os impulsos e dar-thes formas socialmente aceitas e esperadas.

É sabido, também, que todo esse esforço formativo, de caráter pedagógico e social, está sempre carregado de idealizações sobre a condição humana. Nietzsche (1992) analisou e atacou as idealizações. Para ele, toda 4 pretensão de dizer uma verdade é apenas uma entre outras afirmações possíveis e toda vontade de verdade não passa de vontade de poder. Freud (1996; 2006), o pai da psicanálise, confrontou a ideia de uma consciência soberana e onipotente ao afirmar que o sujeito não é movido somente por ações lúcidas. Move-se, muitas vezes, por motivações recalcadas e não disponíveis ao pensamento consciente e imediato. Adorno e Horkheimer (1985), em sua Dialética do esclarecimento, denunciaram que a razão pode tornar-se coisificada, que a indústria do consumo empobrece a cultura e a danifica, deturpando seu significado. As críticas aos resultados da racionalidade moderna são abundantes e contundentes, tanto quanto à dinâmica do sujeito quanto aos resultados sociais dessa dinâmica. $\bigcirc$ sujeito moderno seria, portanto, bem menos livre do que se supunha. Trataria-se, na verdade, de um sujeito demarcado, moldado, ou, ao modo de Marx, radicalmente alienado, não só da sua condição de pensar, mas também expropriado do resultado de seu próprio trabalho.

Há um motor inconsciente e narcísico na mente humana, as pulsões e os instintos é que movem primeiro as ações humanas. Também não somos necessariamente bons, embora possamos nos apresentar assim. Nesse sentido, a necessidade de disciplinamento e de sujeição social dos indivíduos se 
apresentaria como estratégia necessária de moldagem dos comportamentos. Assim, a "educação" seria uma forma de domesticar e adaptar o sujeito na sociedade, conformando-o a uma certa normatividade. Resulta disso, portanto, uma forte suspeita sobre a eficácia da ideia de educar para a emancipação, já que ela não passaria de subordinação a um dado modo de vida.

Essas variáveis não são irrisórias e a pedagogia não pode ficar indiferente a elas. Sabemos que não há teoria pedagógica sem indicativos, sem uma base de normatividade para orientar o agir pedagógico. Porém, se não há uma estrutura estável do sujeito a ser educado e se a emancipação do sujeito através da educação pode não passar de uma fábula, qual normatividade poderia figurar como legitimadora das práticas pedagógicas no processo de formação humana?

\section{Narcisismo e personalização em tempos de subjetividade pós- moderna}

Se a lógica moderna esteve pautada no disciplinamento do sujeito, foi no desdobramento da Modernidade em "Pós-modernidade" que houve o seu abandono progressivo em favor de uma individualização narcísica que parece sem limites. Não pertence aos objetivos do trabalho uma discussão longa sobre a noção de Pós-modernidade. Sinteticamente, operamos com a ideia de que o pós-moderno é um desdobramento da Modernidade, uma radicalização sem par do individualismo e do poder de uma crítica negativa acerca da própria racionalidade. A dinâmica pós-moderna gera um abalo em tudo que parecia absoluto na racionalidade moderna. Denuncia a perda de fôlego das grandes ideologias, e promove uma radical pluralização de nossas sociedades (LIPOVETSKY, 2004)

Não se trata, portanto, de discutir se estamos em uma nova era, se houve uma superação radical da Modernidade ou se estamos tratando dela como um projeto inacabado, ao modo de Habermas (2000), no caso de entendermos que a Modernidade não esgotou a potência de seus conteúdos. Firma-se uma compreensão, ao modo de Vattimo (1992), de que a Pós-modernidade é um fato e que, possivelmente, ainda resulta como uma chance filosófica e, por que não, pedagógica. 
Não dispondo mais de grandes utopias para o futuro e nem de um passado que possa nos redimir, o pós-moderno gerou uma nova temporalidade marcada pelo "predomínio do aqui-agora" (LIPOVETSKY, 2004, p. 59, grifo meu), uma lógica presentista que quer realização, satisfação e eficiência, que busca o imediatismo e o rápido resultado, na base do "tudo já, agora" (LIPOVETSKY, 2005, p. 38, grifo meu).

A sociedade de mercado se impôs de forma soberana e as expectativas revolucionárias não conseguiram explicar ou entender claramente por que erodiram. Silva (2005, p. XIX) aponta que o "socialismo real", do leste europeu, também não escapou à lógica moderna do moralismo, de "[...] uma sociedade baseada no sacrifício". Para o autor, a "[...] ideia de revolução estava contaminada pela noção de disciplina e controle".

A expectativa da luta de classes, ao que parece, foi vencida pela lógica do consumo. A facilidade de crédito otimizou as condições de consumir sem o esforço de poupar ou de alterar a ordem social. $\bigcirc$ consumo de massa ofertou uma suposta noção de igualdade de acesso aos bens que passou a ser a baliza da inserção social do sujeito. $\bigcirc$ capitalismo, ao se impor soberano, continuou e continua a fazer vistas grossas aos excessos do poder econômico, predatório em termos sociais e ambientais, e solenemente ignora tudo o que não gera poder ou mais lucro. "A utopia encolheu", conclui Silva (2005, p. $X I X)$.

Vivemos o hipermoderno, no sentido da exacerbação de um individualismo desobrigado de toda ligação social e a "redução progressiva de sua outra tendência, que é o processo disciplinar", nos diz Lipovetsky (2005, p. 91). Esse sujeito individualista é alguém "preocupado com a felicidade pessoal, de ambições ilimitadas", aponta Charles (2004, p. 15). Prevalece, portanto, o valor da singularidade subjetiva, "[...] o direito de ser absolutamente si mesmo" (LIPOVETSKY, 2005, p. XVII), o que revela uma verdadeira customização da individualidade.

A afirmação do individual sobre o coletivo gerou uma troca no sentido da lógica social do "dever" para a lógica exclusiva do "desejo." A lógica do consumo move o capitalismo através da indústria da moda que renova o apelo pelo inédito contínuo. Para Charles (2004, p. 19), essa nova sociedade apresenta-se marcada pelo efêmero, pela sedução mais do que pelo convencimento argumentativo e "[...] impõe a normatividade não mais pela disciplina, 
mas pela escolha e pela espetacularidade". Prevalecem as questões de gosto, de preferência ou de opinião. $\bigcirc$ indivíduo pode, nesta perspectiva, tranquilamente, realizar-se à parte do social.

Lipovetsky (2005) fala mesmo em uma mudança de formato, do "homo politicus" - sujeito moderno inserido compulsoriamente numa existência e numa demanda coletiva, para o "homo psychologicus" - sujeito pós-moderno, narcísico e inserido numa lógica puramente hedonista. Isso tudo trata da perda do sentido de continuidade histórica, da erosão do sentimento de pertencer, de um soltar-se das tradições. Temos uma subjetividade antes independente do que institucionalizada, antes empreendedora de desejos individuais do que cooperativa, antes particularista e presentista do que preocupada com questões globais ou com o futuro. Busca-se a gratificação do ego, move-se no sentido de uma ética indolor, tênue e minimalista.

Esse sujeito pós-moderno, desafeito a obrigações e sanções, configura uma lógica social na qual "ficou extinta a cultura do sacrifício do dever" que Lipovetsky (2005a, p. 26) denominou como pós-moralista. A paixão pelo dever cumprido, pela honra, pelo compromisso moral de ser um bom cidadão, implicará sempre o sacrifício pessoal diante de algum imperativo ou fundamento. Nessa situação, o sujeito "político" renuncia a um pouco de liberdade pessoal em favor de algum benefício coletivo. No cenário pós-moderno essa lógica se esfuma. A lógica social "pós-moralista", diz Lipovetsky (2005a, p. XXX, grifo meu), é própria de uma "sociedade que repudia a retórica do dever rígido, integral e estrito e, paralelamente, consagra os direitos individuais à autonomia, às aspirações de ordem pessoal", como prioridade absoluta. Uma lógica da subjetividade que se desdobra soberana no terreno movediço do cotidiano, como diz Silva (2005).

Os grandes discursos, ou metanarrativas, das quais falou Lyotard (1998), não passam de "catedrais de palavras" que tentam a fabricação do social com "edifícios teóricos perfeitos por ignorarem o suor e o sangue das práticas concretas" (SILVA, 2005, p. XIV). Como disse Lipovetsky (2005, p. XXIV), vive-se a psicologização do social e do político, uma vida marcada pela expressão plena e contínua da intimidade, principalmente nas redes sociais, como parte de um espetáculo, no exercício do "direito e [do] prazer de se manifestar a respeito de nada", de relações pautadas pelo interesse próprio, da possibilidade de uma "vida sem imperativo categórico" (LIPOVETSKY, 2005, p. 3). 
Essa combinação de sedução e espetáculo sustenta-se na indiferenciação entre espaço privado e espaço público, pois tudo é espaço dessa nova subjetividade. Vemos uma subjetividade particularizada, customizada pela sedução do próprio desejo, numa expansão sem fim das demandas do próprio ego. Configura-se socialmente o que Lipovetsky (2005) denominou como "era do vazio". Esse "[...] marasmo pós-moderno resulta simplesmente da hipertrofia de uma cultura arrematada pela negação de toda ordem estável [...]," conclui o autor (LIPOVETSKY, 2005, p. 62).

pós-moderno colocou em avaliação tudo que era visto como disciplinamento, controle e vontade de poder, mas essa reação "não colocou novos objetos de identificação (símbolos) no lugar daqueles que foram rejeitados" (SILVA; VIANA, 2015, p. 15). Vive-se a relativização contínua do valor do conhecimento e da tradição. Há uma ânsia pelo absolutamente novo. E não apenas o novo, mas o inédito, o "diferencial", o "exclusivo", o "particular." Propala-se a ideia de que todos podem ser "protagonistas" de si, sem a necessidade de ter de suportar o "outro". Com isso, temos uma sobrecarrega das exigências do tempo presente e uma ansiedade que o sujeito não pode e não consegue saciar. $\bigcirc$ sujeito epistêmico da Modernidade torna-se fragmentado, 8 dissolvido, jogado no vazio, descolado do social, perdido na esfera do imediatismo e do consumo, sem causas, desafeito às ideologias, desinteressado pelo que é coletivo. Como bem sublinhou Gomes (2018, p. 46), vemos "[...] a dimensão cooperativa e social do eu enclausurada".

\section{A configuração narcísica e o sujeito contemporâneo na era do vazio}

Para Freud (2006a), a estruturação psíquica da sociedade segue os mesmos preceitos do que ocorre com os indivíduos, porém de forma expandida. Ele entendia que a civilização trazia a exigência de converter os impulsos espontâneos e adiar a sua satisfação. Isso seria possível fazendo com que o objeto final não fosse mais o objeto primário, de cunho sexual, hedonista, voltado ao próprio prazer, mas um substituto mais próximo da cultura. Para Freud, seria graças a esse processo de sublimação, ou seja, de desvio da energia pulsional da satisfação imediata para um objeto "mais elaborado" que ocorreria o progresso da cultura. E é justamente no "[...] declínio do poder dos sustentáculos institucionais simbólicos da cultura [...]" que estaria a motivação 
do narcisismo exacerbado da sociedade pós-moderna, apontam Silva e Viana (2015, p. 10).

As pulsões enobrecidas (sublimadas), não cancelam os impulsos primitivos. No entanto, a civilização e a cultura somente podem ser asseguradas com restrições dessa ordem. Freud (2006) apontou que o impulso desejante continua a sua existência, mesmo quando reprimido ou sublimado e, havendo uma oportunidade, irá manifestar-se. A interdição da satisfação imediata, em excesso, seria produtora de neuroses que se expressariam em sintomas diversos.

Quando o conteúdo dos desejos do sujeito mostra-se incompatível com o seu próprio julgamento ou com as sanções morais do seu meio, o sujeito poderia dirigir seu desejo para um alvo irrepreensível e mais elevado e, com isso, aliviar a sua tensão interna, compreendendo como justa a solução. Porém, não havendo a permuta de destino do desejo do sujeito e, portanto, a frustração do desejo primário e a sua troca por uma realização "irrepreensível", teríamos o avanço do desejo narcísico na busca de ter todas as suas expectativas satisfeitas.

funcionamento narcísico ocorre, portanto, quando o sujeito não transfere a energia dos seus desejos para objetos externos, nem consegue fazer o ajuste da forma de sua realização (sublimação), dedicando a si mesmo o investimento do desejo (ROUDINESCO; PLON, 1998). Os autores ponderam que o investimento de energia nos próprios desejos coexiste e pode equilibrar-se com o investimento em objetos externos. A situação adversa estaria na impossibilidade de o sujeito dar um destino a seu desejo que não seja somente para causas próprias. $\bigcirc$ sujeito narcísico vê como sofrimento a postergação da satisfação ou a substituição do "destino" de realização de desejo. Com isso, enfrenta dificuldades em considerar perspectivas que não sejam somente as suas ou de seu interesse.

sujeito pós-moderno, nesta configuração de funcionamento psíquico, acaba lançado ao vazio e ao desamparo pois a satisfação pessoal requer um viver para si sem os outros, sem desnarcisar-se. Ocorre que, neste direcionamento para si, o sujeito fica esvaziado do afeto que poderia ser obtido do reconhecimento do outro. Fica empobrecido da noção de empatia e de coletividade. Ao modo freudiano, fica mais focado na condução da vida pelo princípio do prazer, movido mais pela satisfação sem restrições às demandas do ego, do que pelo princípio da realidade, sem a necessária imposição 
de restrições ou adiamentos aos desejos do ego. $\bigcirc$ sujeito passa a viver o vazio do qual falou Lipovetsky, numa espécie de solilóquio emocional em que o próprio vazio é o conteúdo. Porém, ainda que desejasse, não poderia viver somente para si, sem os efeitos do ambiente, do externo e do outro que ele mesmo recusa.

Se, durante o século XIX e começo do XX, a neurose, especialmente na forma de histeria, era a forma mais evidente de sofrimento psíquico, no século XXI esse espaço foi tomado pela depressão, que representa, atualmente, o mais frequente diagnóstico psiquiátrico (PEREIRA, 2018). Os quadros depressivos movimentam um poderoso mercado farmacológico que se alimenta da miséria simbólica sobre as quais as patologias narcísicas se edificam.

Os estudos sobre o sujeito na contemporaneidade apontam para a "busca imperativa da felicidade" como consequência do declínio do regime disciplinar moderno. Busca insaciável, de alcance difícil, legitimada como exigência para a exibição social e, por isso mesmo, geradora de angústia e sofrimento contínuo. Nesse caso, nós, sujeitos contemporâneos, nos tornamos causa e vigias de nós mesmos, porém, e inevitavelmente, "[...] nossos avalistas continuam a ser os outros" (PEREIRA, 2018, p. 38).

10 Sobre a questão do sofrimento humano, o próprio Freud já havia sinalizado, em texto de 1930, que:

O sofrimento nos ameaça a partir de três direções: de nosso próprio corpo, condenado à decadência e à dissolução, e que nem mesmo pode dispensar o sofrimento e a ansiedade como sinais de advertência; do mundo externo, que podem voltar-se contra nós com forças de destruição esmagadoras e impiedosas; e, finalmente, de nossos relacionamentos com os outros homens. O sofrimento que provém desta última fonte talvez nos seja mais penoso do que qualquer outro (FREUD, 1996, p. 141, grifos meus).

Entregue à própria miséria simbólica, aos mandos de uma frustração incontornável, o sujeito verte-se num corpo de dor psíquica. Somatiza o sofrimento e gera efeitos colaterais de ordem clínica e comportamentos impulsivos como forma de resolver o sofrimento, embora sem eficácia porque seus desdobramentos são destrutivos ao próprio sujeito. Essa dinâmica, destacam Souza e Kosovski (2018, p. 166), gera mais sofrimento para o sujeito e acentua a noção de desamparo, abandonado e perdido no sofrimento que se corporifica. No mundo do espetáculo, "máscaras e adornos" transformam o corpo em 
palco do espetáculo do ego, da exibição de si. $\bigcirc$ narcisismo funciona como "[... tentativa compensatória [...]" do vazio, mas acaba aprofundando e alargando a falta de sentido.

Na prática, ao acentuar a radicalidade deste individualismo, com profundos "danos ao sentimento de si" (CARDOSO, 2015), poucos são os ganhos para esse sujeito. Ao contrário, ele fica enredado numa dinâmica que gera perda de singularidade. Não há o que seja suficiente para distinguir-se ou elevar-se na cultura de massa da propaganda e do espetáculo cotidiano da intimidade. Sucumbe o sujeito transcendental, virtuoso e racional, dotado de uma essencialidade universal (sujeito epistêmico), uma verdadeira "categoria cognitiva e moral" (GOMES, 2018), em favor de um sujeito esfacelado e em sofrimento contínuo.

\section{Para finalizar: das relações entre pedagogia, formação e sujeito pós- moderno}

A Modernidade gerou uma certa gramática pedagógica sobre o ensinar e o aprender a partir de pressupostos derivados, principalmente, da filosofia iluminista: a busca da perfectibilidade humana, o melhoramento intelectual e moral do sujeito e a sua inserção como pessoa capaz de inserir-se em uma vida pública através do trabalho e da atuação política como homem civil, o cidadão.

No cerne da ideia de uma formação "humanista" está o entendimento, ao modo kantiano, de que o homem será aquilo que a educação fizer dele. Nessa perspectiva, tipicamente moderna, o sujeito somente poderá superar a sua "menoridade" se aprender a domar os seus impulsos (adquirir disciplina) e apropriar-se dos produtos da cultura (adquirir instrução) para ser capaz de fazer de julgamentos considerados bons frente a uma dada comunidade (adquirir moralidade), perfazendo a integralidade do projeto formativo.

A complexa tarefa da formação humana foi institucionalizada na Modernidade como dever do Estado a ser cumprida através da escola obrigatória, laica e universal. Numa perspectiva, esse projeto pode ser visto como um modo de enquadramento social dos humanos. Por outro lado, pode ser visto como uma oportunidade social de "desnarcisar" o sujeito, uma vez que a vida em sociedade é uma contingência e é preciso aprendê-la. À escola coube servir-se dos artefatos da cultura e da ciência para promover instrução e inserir 
o indivíduo em práticas socializadoras, fazendo o trânsito entre o espaço privado, regulado pela família, e o espaço público do convívio social, regulado pelo Estado como dimensão coletiva. "Para combater a imoralidade e a indisciplina dos costumes individualistas, os modernos sacralizaram a escola como dever moral e cívico [...]", destacou Lipovetsky (2005a, p. 6).

A vida cotidiana na escola funciona como instância de mediação entre essas duas instâncias, as vontades privadas e a vida pública, e essa, como sabemos, sempre exige renúncias. A dinâmica social, de ordem prático-moral, exige da criança e do jovem o aprendizado de avaliar as suas vontades e impulsos em relação às possibilidades de sua realização. Para isso, deverá aprender a praticar a avaliação racional das possiviveis consequências dos seus proferimentos e de suas ações. Os professores e professoras serão as primeiras figuras de autoridade fora do eixo familiar com quem as crianças deverão confrontar-se nesse lugar público e institucional chamado escola. Essa instituição formativa, herdeira da Modernidade, funciona sob a tutela do Estado de forma direta, no caso das redes públicas, ou indireta, no caso das redes privadas. A escola tem seus regulamentos, lida com conflitos, com questões de justiça. Confrontos de ideias e de atitudes ocorrem diariamente e precisam 12 ser mediados. Nessas situações, a lei precisa ser aplicada, assim como os direitos precisam ser garantidos e as obrigações, cumpridas. A escola, além da instrução formal, apresenta-se como um campo de experiência oportuno e necessário para o aprendizado da vida pública e para desnarcisar o sujeito.

Nessa missão social da escola moderna, "[...] a despeito das boas intenções, o que se produziu foi pouco [...]", pondera Rosa (2013, p. 37). A escola ficou tomada de procedimentos, disciplinamentos contínuos, adotou didáticas muitas vezes artificiais e abstratas. Sobram críticas ao que se denominou como pedagogia tradicional: livresca, autoritária e desconectada do mundo real das crianças e jovens, uma "escola opressiva" que teve como obra maior promover consensos sociais, manipulações ideológicas e destruir singularidades, prossegue a autora (ROSA, 2013).

Os modelos pedagógicos libertários, por sua vez, não produziram resultado melhor ao longo da história. Ao contrário, as pedagogias que postularam a criança como centro do trabalho pedagógico, e tomaram seus interesses imediatos e curiosidade natural como eixo de trabalho, são acusadas de serem permissivas. Isso por terem se ocupado, em demasia, em atender aos desejos das crianças e dos adolescentes. Os seus críticos dizem que, ao agir assim, 
fomentam a manutenção do sujeito colado às demandas de gratificação do ego, sem aprender a renunciar ou aguardar a realização de seus desejos. Esse caminho alimentaria o que Lebrun (2008) chamou de "todo-poder infantil" e isso resulta em um adulto narcisificado, biologicamente maduro, porém emocionalmente infantil.

Para Voltolini (201 1), é preciso compreender que a educação tem, sim, um caráter conservador intrínseco. Aprender a controlar as pulsões e adaptar-se ao meio social faz parte do metabolismo social que transforma a "criança-rei," que tudo pode, num adulto que faz escolhas possíveis. Enquadrado, assujeitado, reprimido, moldado? Sim, nesse sentido alguma coerção é necessária para que se obtenha o domínio dos impulsos, para que o sujeito possa "viver-com" sem formas violentas, com capacidade de negociar, de argumentar sobre posições que deseja. O autor afirma que o sujeito ama e odeia a cultura, pois ela possibilita medidas de satisfação ao ego, conquistas sociais que o gratificam, mas impõe contínuas renúncias. Fora disso, é a produção da barbárie, conclui Voltolini (201 1).

A ideia pedagógica de defesa da individualidade da criança como definidora dos rumos da formação, como sugeriu Rousseau (1995) para educar Emílio, em fins do século XVIII, coexiste com outros preceitos, como o do ensino de massa, do ensinar tudo a todos, tão bem formulado pela didática comeniana, ainda no século XVIII. Essas formulações pedagógicas estão costumeiramente resumidas em dois conjuntos de enunciados: a pedagogia tradicional e a pedagogia nova. Cosme e Trindade (2013) sintetizaram essas duas vertentes como a tradução de dois modelos pedagógicos: a escola dita "tradicional" marcada pelo paradigma da instrução e a escola dita "nova" marcada pelo paradigma da aprendizagem.

A pedagogia dita "tradicional" (paradigma da instrução) está centrada no ensino e na condução pedagógica dos adultos. É a marca registrada da escola moderna de massa, institucionalizada, construída no fim do século XVIII e no decorrer do XIX, a partir da máxima comeniana do "ensinar tudo a todos como se fossem um". Para a época, esse modelo representou, reconheçamos, um importante avanço ao democratizar o acesso à instrução. A pedagogia dita "nova" (paradigma da aprendizagem) nasceu no fim do século XIX e popularizou-se nas três primeiras décadas do século XX, inclusive no Brasil. Está centrada no aluno e no processo de aprender pela própria experiência, deixando aos adultos um papel coadjuvante. Ambas derivam da 
A pedagogia, a formação humana e o sujeito narcísico pós-moderno

mesma fonte moderna, seja em vertentes mais cognitivistas ou mais experimentais, e continuam sendo reinventadas até os dias atuais.

Rousseau (1995), com a publicação de Emílio ou da educação, em 1762, propugnou um modelo de educação naturalista e individualizada que influenciaria toda a pedagogia moderna e que nada tem a ver com o paradigma da instrução. De um lado, customiza o processo pedagógico ao desenvolvimento particular da criança, que deveria ser educada de forma personalizada. De outro, tem uma finalidade muito bem definida, a formação para a virtude. O caminho é personalista para melhor ajustar ao caminho do êxito, para que a criança não prospere em suas "inclinações naturais", que devem ser superadas. Essa base nutriu toda a pedagogia da escola nova e o paradigma da aprendizagem.

Cambi (1999) apontou que a crítica ao autoritarismo na educação já estava presente no pensamento de John Locke (1632-1704), que condenava as punições corporais. O pensador inglês via na figura do "gentleman" o modelo ideal para formar os jovens. Eles seriam elevados em suas virtudes e conhecimentos para que pudessem adquirir capacidade de renunciar aos próprios desejos e inclinações espontâneas e seguir "[... ] unicamente aquilo que a razão 14 The indica como melhor" (CAMBI, 1999, p. 317). No século XVIII e, depois, no XIX, a educação foi cada vez mais laicizada e reforçou a ideia de ser a chave mestra da vida social (CAMBI, 1999). Pensadores como Rousseau, Pestalozzi, Kant, Basedow e, depois, Herbart, Comte, e mesmo Marx, apontaram, de forma direta ou nos entremeios de suas obras, nuances do que se poderia chamar de pedagogia "humanista." Esse nascedouro intelectual moderno aponta que o ideário pedagógico transita entre a individualidade e a vida coletiva como propósito educativo em diferentes narrativas pedagógicas, mas todas possuem suas raízes no mesmo tronco.

A pedagogia do século XX aprendeu rápido que não pode tudo, que existem limites. Isso deu-se, principalmente com a ampliação da matrícula para distintos públicos (universalização do acesso à escola) e a consequente pluralização do público escolar. Avança a educação feminina com o surgimento das escolas mistas e surgem novas noções acerca da infância. $\bigcirc$ atendimento a pessoas com deficiência e os processos de inclusão conquistam espaço. Amplia-se o acesso à escola a pessoas de etnias e de condições sociais que antes não a frequentavam. A escola cada vez menos "[...] se refere a um ideal civilizatório comum" (CAMBI, 1999, p. 47). Aliás, na prática, ele seria mesmo 
impossível. A diversidade do público escolar se impõe como um fato próprio dos tempos pós-modernos e isso ocorre de forma radicalizada.

A expectativa moderna de formação do "sujeito educado" persiste, embora com mais dificuldades. A questão é que, gostemos ou não, a "humanização" tem como eixo necessário o "interdito", ou seja, é preciso educar o sujeito na prática da renúncia da satisfação das suas vontades imediatas, na prática do aprender a conter seus impulsos agressivos e sexuais (CIFALl; IMBERT, 1999). Nesse sentido, humanizar significa incorporar a capacidade de fazer renúncias para não perecer diante das catástrofes geradas pelo voluntarismo narcísico. $\bigcirc$ desdobramento das práticas pedagógicas no cenário escolar pluralizado enfrenta, portanto, maiores embaraços na sua expectativa de êxito e nas condições práticas, nada ideais, de sua atuação.

Nenhum processo educativo obtém êxito, necessariamente, por estar vinculado ao paradigma da instrução ou ao paradigma da aprendizagem, ou mesmo a outro qualquer que possa ser nominado. A complexidade da formação humana desenvolvida na escola também não pode ser reduzida num paradigma ou explicação. Voltolini (2011) nos lembra que as formulações e os grandes enunciados sobre a formação não garantem os seus resultados. Do mesmo modo que um educador consciente, apesar de suas possíveis boas intenções, jamais terá controle sobre os efeitos de sua influência sobre seus alunos.

A educação vista como "tradicional" costuma receber críticas por ser opressora, burocrática e desconectada das necessidades e dos interesses das crianças e dos jovens. No entanto, a educação vista como "progressista" costuma fazer críticas degenerativas à ideia de autoridade e deixar as crianças escolherem livremente, como se fosse possível não influenciá-las, pondera Voltolini (201 1). As pedagogias progressistas relativizaram a figura dos adultos colocando-os no lugar abstrato de "mediador", portanto, "entre" a criança/ jovem e o conhecimento, gerando um esvaziamento da força da referência e do modelo de vida adulta. Com qual orientação pedagógica poderemos prosseguir?

Nesse caminho reflexivo, ficaria o desafio de buscar a "justa medida", uma linha do razoável, do possível. $\bigcirc$ excesso de dirigismo e de repressão conduz à formação de neuroses, mas o excesso de liberdade e a falta de parâmetros ao ego conduz à formação da perversão. Qualquer finalidade estabelecida para as funções pedagógicas será problemática, mas há um 
papel que foi atribuído à escola e que pode ser atualizado, o de servir de instância de diálogo e de prática concreta entre as demandas privadas do indivíduo e as da cultura em que ele está inserido.

Diante deste individualismo indomado dos tempos pós-modernos, poderemos colocar em risco as próprias conquistas da civilização se aderirmos, sem resistência reflexiva, à ideia de que "nada mais há." Há boas razões para fomentar na escola o treino prático do enfrentamento dos traumatismos e dificuldades da vida coletiva, próprias do "viver-com" e o aprendizado pessoal que podemos ter com as renúncias impostas pela cultura. Abdicar a essa perspectiva será continuar fomentando a permanência, nos adultos, de uma organização emocional assentada num "todo-poder" que não pratica renúncias. Ao banalizar a própria existência e as necessidades do outro, o sujeito sucumbe no próprio vazio, entregue ao gozo mortífero (LEBRUN, 2008).

É preciso lembrar que um dos grandes discursos da educação -educação para o pensar, para a autonomia, para a criatividade e para papéis ativos e responsáveis no mundo - não se edifica sobre bases narcísicas e voluntaristas. Voltolini (2011) aponta que o pensar independente implica e requer sustentação sem apoio no vazio, enquanto a vida durar. Essa dinâmica é com16 plexa, de difícil realização e exige uma autonomia muito bem constituída. Para isso, é preciso ter-se apoiado num outro sujeito que já se sustentava no vazio. A criança e o jovem precisam de modelos, de referências de quem enfrentou o desafio de desnarcisar-se minimamente, alguém que aprendeu que não existe um desejo ilimitado possível de ser saciado. $\bigcirc$ excesso de negociação, seguida por muitas famílias e escolas, é uma armadilha. Favorece a fantasia infantil de "todo-poder" e a ideologia da felicidade no "aqui e agora", o tempo todo. A vida coletiva é, inevitavelmente, imprevisível e sem garantias de realização dos nossos desejos particulares.

Mesmo com o cenário pós-moderno, que enfatiza o individualismo pleno e sugere que todos podemos ter a precedência de nossas vontades, aprender a lidar com as limitações e sofrimentos que a vida nos reserva é um conteúdo pedagógico dos mais relevantes se não quisermos desfazer definitivamente o tecido social. Sem laço social, o destino é a barbarização. Não bastará buscar refúgio em modelos pedagógicos que habitam um passado idílico. Ele não está lá. Também não está na tecnologia ou nas plataformas digitais, nas metodologias ativas, no ensino híbrido ou no ensino domiciliar que surgem como os anúncios do futuro pedagógico bem-sucedido. E pode 
estar em todas essas opções. Podemos investir na reinterpretação dos fundamentos do humanismo moderno, a partir de seus autores clássicos, e do que eles ainda podem nos dizer. Também podemos avaliar criticamente as pretensões de validade das reinterpretações da escola nova que povoam os atuais discursos educativos.

É preciso enfrentar o vazio para que possamos ainda investir em formas de vida não fracassadas, violentadas. É possível enfrentar o vazio da precariedade dos laços simbólicos no processo educativo escolar para não sucumbirmos à barbárie. $\bigcirc$ vazio, do qual falou lipovetsky, não é só de referências do passado ou de projeções mobilizadoras do futuro para dar sentido à vida. É o pior e mais difícil dos vazios, é o vazio de uma vida presente que, sem sentido, transformou-se em vácuo.

\section{Referências}

ADORNO, Theodor; HORKHEIMER, Max. Dialética do esclarecimento. Tradução Guido Antonio. Rio de Janeiro: Zahar, 1985.

CAMBI, Franco. História da pedagogia. Tradução Álvaro Lorencini. São Paulo: Editora UNESP, 1999.

CARDOSO, Claudia Rodrigues. A construção da subjetividade contemporânea e sua relação com a depressão. Cadernos de Psicanálise - CPRJ, Rio de Janeiro, v. 37, n. 32, p. $17-41,2015$.

CHARLES, Sebastien. $\bigcirc$ individualismo paradoxal: introdução ao pensamento de Gilles Lipovetsky. In: LIPOVETSKY, Gilles. Os tempos hipermodernos. 3. reimp. Tradução Mario Vilela. São Paulo, Barcarolla, 2004.

CIFALLI, Mireille; IMBERT, Francis. Freud e a pedagogia. Tradução Maria Gonçalves e Adail Sobral. São Paulo: Loyola, 1999.

COSME, Ariana; TRINDADE, Rui. Organização e gestão do trabalho pedagógico: perspectivas, questões, desafios e respostas. Porto: Mais, 2013.

FOUCAULT, Michel. Vigiar e punir - nascimento da prisão. 27. ed. Petrópolis: Vozes, 1987. 
FREUD, Sigmund. O malestar na civilização. Tradução Durval Marcondes. Rio de Janeiro: Imago, 1996.

FREUD, Sigund. Cinco lições de psicanálise. Tradução Durval Marcondes. Rio de Janeiro: Imago, 2006.

FREUD, Sigmund. Três ensaios sobre a teoria da sexualidade. Tradução Durval Marcondes. Rio de Janeiro: Imago, 2006 a

GOMES, Carlos. Ortega y Gasset: no caminho da hipermodernidade - uma visão projetiva da contemporaneidade. Ideias y Valores, Bogotá, v. 67, n. 168, p. 43-57, 2018 . DOl: http://doi.org/10.15446/ideasyvalores.v67n 168.59512.

HABERMAS, Jürgen. A ética da discussão e a questão da verdade. Tradução Marcelo Cipolla. São Paulo: Martins Fontes, 2004.

HABERMAS, Jürgen. Discurso filosófico da modernidade. Tradução Luiz Repa e Nascimento. São Paulo: Martins Fontes, 2000.

KANT, Imanuel. Sobre a pedagogia. Tradução Francisco Fontanella. 2. ed. Piracicaba, UNIMEP, 1999.

18 LEBRUN, Jean-Pierre. A perversão comum - viver juntos sem outro. Tradução Procópio Abreu. Rio de Janeiro: Companhia de Freud, 2008.

LIPOVETSKY, Gilles. Os tempos hipermodernos. 3. reimp. Tradução Mario Vilela. São Paulo, Barcarolla, 2004.

LIPOVETSKY, Gilles. A era do vazio - ensaios sobre o individualismo contemporâneo. Tradução Therezinha Deutsch. Barveri: Manole, 2005.

LIPOVETSKY, Gilles. A sociedade pós-moralista - o crepúsculo do dever e a ética indolor dos novos tempos democráticos. Tradução Armando Braio. Barueri: Manole, 2005a.

LYOTARD, Jean-François. A condição pós-moderna. Tradução Ricardo Barbosa. 5. ed. Rio de Janeiro: José Olympio, 1998.

NIETZSCHE, Friedrich. O nascimento da tragédia, ou helenismo e pessimismo. Tradução Jacob Guinsburg. 2. ed. São Paulo, Companhia das Letras, 1992.

PEREIRA, Claudia Rodrigues. A construção da subjetividade contemporânea e sua relação com a depressão. Cadernos de Psicanálise - CPRJ, Rio de Janeiro, v. 37, n. 32, p. 17-41, jan./jun. 2015 
ROSA, Sanny. Pinóquio e a escola hipermoderna: reflexões sobre o sentido da educação na sociedade contemporânea. Revista de Ciências Humanas, Florianópolis, v. 47, n. 1, p. 34-49, abr. 201 3. DOl: https://doi.org/10.5007/2178-4582.2013v47n 1 p34.

ROUDINESCO, Elisabeth; PLON, Michel. Dicionário de psicanálise. Tradução Vera Ribeiro e Lucy Magalhães. Rio de Janeiro: Zahar, 1998.

ROUSSEAU, Jean-Jacques. Emílio ou da educação. Tradução Sergio Millet. 3. ed. Rio de Janeiro: Bertrand Brasil, 1995.

SILVA, André; VIANA, Terezinha. A deficiência simbólica na subjetividade pós-moderna: bases para uma sociedade narcísica. Barbarói, Santa Cruz do Sul, n. 45, p. 9-29, jul./ dez. 2015. DOl: http://dx.doi.org/10.17058/barbaroi.v0i0.7073.

SILVA, Juremir Machado. Vazio e comunicação na era do "pós-tudo". In: LIPOVETSKY, Gilles. A era do vazio - ensaios sobre o individualismo contemporâneo. Tradução Therezinha Deutsch. Barueri: Manole, 2005.

SOUZA, Danuza Effegem; KOSOVSKI, Giselle Falbo. Mulheres e espelhos: a devastação e o irrepresentável no corpo feminino. Fractal - Revista de Psicologia, Rio de Janeiro, v. 30, n. 2, p. 166-172, jan./abr. 2018. DOI: https://doi.org/10.22409/1984-0292/ v30i2/5504.

VATTIMO, Gianni. A sociedade transparente. Tradução Hossein Shooja e Isabel Santos. Lisboa: Relógio D’água, 1992.

VOLTOLINI, Rinaldo. Educação e psicanálise. Rio de Janeiro. Zahar, 2011.

Prof. Dr. João Francisco Lopes de Lima Universidade do Porto (Portugal) Faculdade de Psicologia e de Ciências da Educação Programa Doutoral em Ciências da Educação ORCID ID: http: / / orcid.org/0000-0002-0 $188-2354$ E-mail: jfrancisco.lima@gmail.com Recebido 16 maio 2019 Aceito 25 jun. 2019 